\title{
Analysis of profit efficiency among smallholder sheep farmers of N8 development corridor Free State, South Africa
}

Yong Sebastian Nyam ( $\square$ yongsebastian04@gmail.com )

University of the Free State https://orcid.org/0000-0001-7175-2873

TEMITOPE OJO

University of the Free State

Amate Johannes Belle

University of the Free State

Abiodun Ogundeji

University of the Free State

Adetoso Adetoro

University of the Free State

Research

Keywords: profitability, stochastic profit function, profit efficiency; inefficiency, sheep production, South Africa

Posted Date: April 15th, 2020

DOl: https://doi.org/10.21203/rs.3.rs-22371/v1

License: (c) (1) This work is licensed under a Creative Commons Attribution 4.0 International License. Read Full License 
Title: Analysis of profit efficiency among smallholder sheep farmers of $N 8$ development

2 corridor Free State, South Africa

3 Abstract

4 The livestock sector is the largest agricultural-sub sector in South Africa contributing 5 approximately $30 \%$ to the agricultural output. The aim of this research is to measure the profit

6 efficiency of smallholder sheep farmers and to identify the factors affecting profit efficiency of the

7 farmer, in order to propose better strategies for sustainable livestock production among

8 smallholder farmers in the Free State. A stochastic profit frontier approach was used to evaluate

9 the profitability and efficiency of 217 smallholders in the N8 development corridor Free State,

10 South Africa. The results found that the farmers are not efficiency and have great capacity to

11 improve profitability in sheep production. The result showed that Profit efficiencies of the farmers

12 varied between $15.5 \%$ and $80.4 \%$ with a mean of $65.1 \%$ implying that an estimated $34.9 \%$ of the

13 profit is lost due to a combination of economic and allocative inefficiencies in sheep production.

14 The study found that profit efficiency is positively influenced by level of education and household

15 size (members below 18 years old) while gender and sheep loss increase profit inefficiency. Profit

16 efficiency of the farmers can be significantly increased through effective education and training of 17 farmers.

19 Keywords: profitability, stochastic profit function, profit efficiency; inefficiency, sheep production, South Africa

\section{Introduction}

23 Livestock production makes an important contribution to most economies around the world, 24 especially developing economies that depend largely on livestock production for their livelihoods 25 (Tamirat, 2013). Livestock production is important because it is a source of wealth creation and 26 improves the livelihoods of rural poor households (Ndoro et al. 2014). Smallholder livestock 27 production is a major economic occupation and creates employment for approximately $70 \%$ people 28 in rural areas around the world (Poole 2017). The livestock production contributes approximately $2945 \%$ of South Africa's agricultural output and provide employment for approximately 500000 
people (South Africa Department of Agriculture, Forestry and Fisheries (DAFF) 2012). Livestock production contributes between $25 \%$ and $30 \%$ annually to South Africa's national agricultural gross domestic product (GDP) (Ngarava et al. 2019).

Sheep production plays a very important role in the South African livestock industry, because it is a source of cash income and therefore contributes to smallholder farmers' livelihood (Brundyn et al. 2005). Sheep production provides food security, enhances crop production (by providing manure), generates income for smallholder farmers, provides fuel for transport and produces value-added goods that can have a multiplier effect and help create a need for further services (FAO 2012). Smallholder livestock farmers play a major role in enhancing livestock production in South Africa. South Africa has an estimated 28.8 million sheep, of which 7.4 million are owned by smallholder farmers and 21.4 million owned by commercial farmers (Molotsi et al. 2017). This shows that commercial farmers who produce and supply the local and international markets dominate the sheep industry in South Africa. Even though the market is dominated by commercial farmers, South Africa remains a net importer of sheep and sheep products (Nyam et al. 2019). Factors such as, consumer preferences, changing lifestyle, globalisation, high population and income growth have increased the demand for sheep and sheep products in the local market (Rios et al. 2009). Climate change especially drought and increasing production cost has slowed down sheep production in South Africa (Molotsi et al. 2017). This gap between demand for and supply of sheep and sheep products has provided a great opportunity for integrating smallholder sheep farmers into the value chain (Ndoro et al. 2015). However, the inability of smallholder sheep farmers to exploit the full potential is due to inadequate infrastructure, lack of management skills, inadequate feed resources, as well as inadequate techniques for genetic improvement of their livestock (Rege et al. 2011). These constraints are inhibiting the performance of smallholder farmers, their profitability and competiveness in the local and international markets.

Previous studies have examined livestock production and market participation of smallholder livestock farmers in South Africa (Rios et al. 2009; Mafukata 2015; Ndoro et al. 2014; Ndoro et al. 2015; Ngarava et al. 2019; Molotsi et al. 2017; Bahta and Bauer 2012), market factors inhibiting the competitiveness or profitability of smallholder farmers (Mpandeli and Maponya, 2014; Dlamini, 2014), technical efficiency and technological gap in sheep production (Nyam et al. 2019). The limitations of these studies lie in that they did not account for factors influencing the 
60 profitability and profit efficiency of smallholder farmers, and only assumed technical efficiency in 61 terms of input use and production technology. Furthermore, Nyam at al. (2019) only focused on 62 the technical efficiency and technological gap that exist between smallholder sheep farmers and 63 failed to estimate the economic and allocative efficiencies of the smallholder farmers. Economic 64 and allocative efficiencies are important to determine the profit efficiency and competitiveness of 65 farmers. The above limitations makes the study important because efficiency is estimated and 66 examined for its actual and potential influence on profitability, competitiveness and the factors 67 affecting them. Similar studies in Africa (e.g. Tijani et al. 2006; Mawa et al. 2014; Bahta and 68 Baker, 2015; Ojo et al. 2020) have analysed the profit efficiency of smallholder farmers. However, 69 there is limited information available in South Africa on the profit efficiency of smallholder sheep 70 farmers, thereby, making this study very relevant.

71 The aim of this paper was to measure the profit efficiency (PE) of smallholder sheep farmers and 72 identify the factors affecting it in order to propose strategies for an integrated livestock sector. The 73 stochastic profit frontier approach is used to measure the PE and determine the factors influencing 74 sustainable livestock production. The profit frontier is useful for providing information to policy 75 makers on the effect of socio-economic indicators on profit inefficiency (Bahta and Baker 2015). 76 Given the gap between the demand for and supply of livestock in the local market, identifying the 77 determinants of profit efficiency will inform policy makers of the best policy options for 78 developing an inclusive market system and enhancing profitability of sheep production. To better, 79 understand the factors influencing profit efficiency and inefficiency, and enhance sheep production 80 and profitability, this study estimates profit efficiency for Thaba Nchu and Boshabelo as a single 81 profit function (pooled).

82 The paper is organised as follows: study area is discussed in section two, while the methodological

83 approach, which includes the empirical estimation followed in the study and the descriptive 84 analysis, is explained in the third section. Results are presented and discussed in section four. 85 Finally, some conclusions and policy implications of such findings are discussed in the final 86 section. 


\section{Study area and data}

\subsection{Study area}

91 This study was conducted in the N8 development corridor, Free State province of South Africa

92 (Figure 1). The Free State province is located in the central part of South Africa and is one of nine 93 administrative provinces of South Africa. The Free State province is situated between latitude $9426.6^{\circ} \mathrm{S}$ and $30.7^{\circ} \mathrm{S}$ and between longitude $24.3^{\circ} \mathrm{E}$ and $29.8^{\circ} \mathrm{E}$. The province has a total land 95 surface area of approximately $129825 \mathrm{~km} 2$, accounting for an estimated $10.6 \%$ of the country's 96 land area (Davis et al. 2006). It is the second-largest province in South Africa alongside Western 97 Cape and shares borders with Gauteng, Mpumalanga, North West, KwaZulu-Natal and the 98 Kingdom of Lesotho. Crop production and mixed livestock production are the main agricultural 99 activities of the Free State province. Livestock production is a key economic activity in the 100 province and the study area. The Free State is home to large farms that keep cattle for beef and 101 dairy production, sheep and goats and, to a lesser extent, poultry and pigs. The Free State 102 contributes $20 \%$ of sheep, $20 \%$ of beef and $40 \%$ of goats produced in South Africa (Maphalla and 103 Salman 2012).

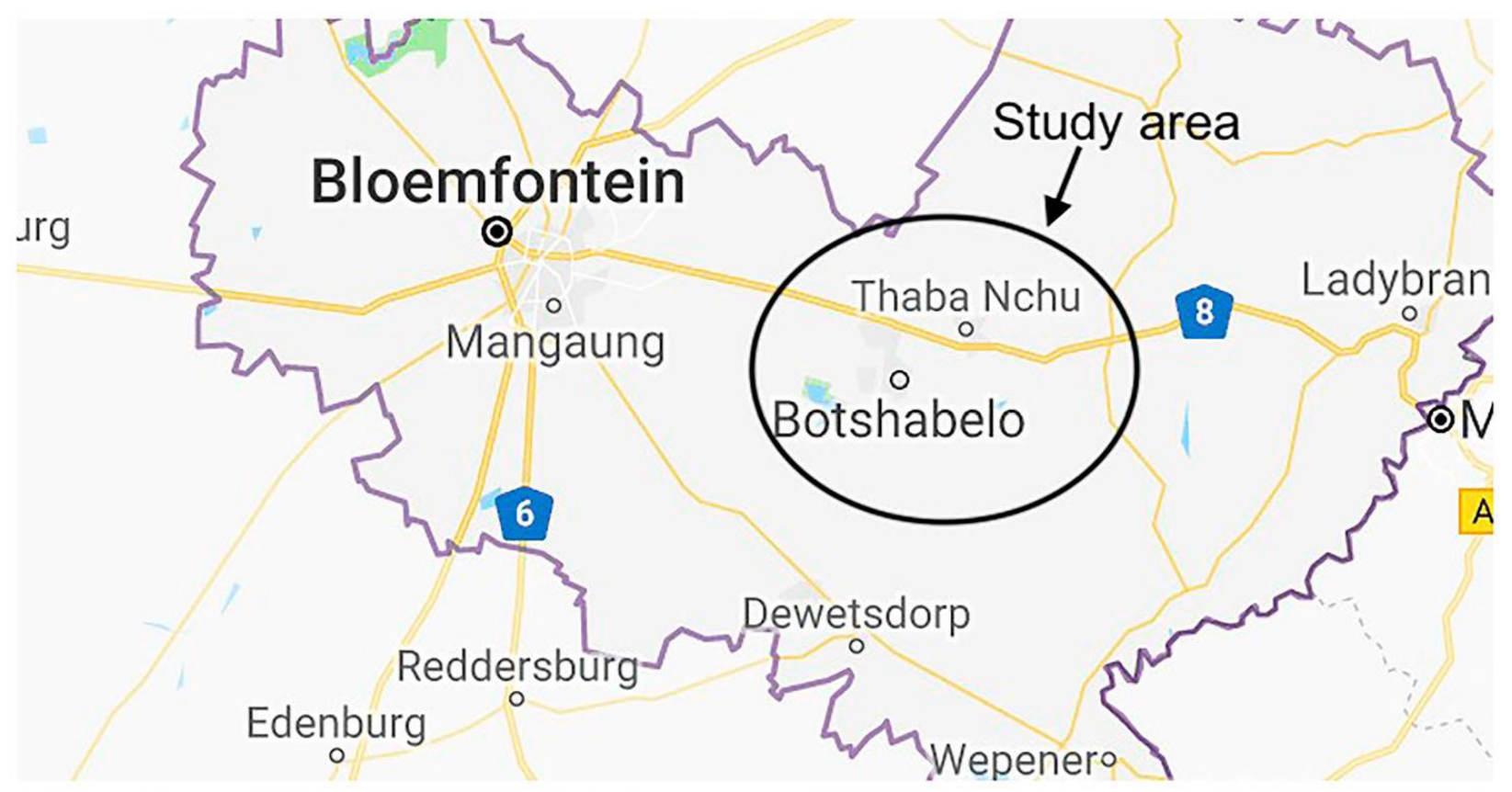

105 Figure 1: Map of the research area within the Mangaung metropolitan.

106 Source: AfriGIS (Pty) Ltd. (2019). 


\subsection{Sources of data and sampling procedure}

Data for this study were collected using structured questionnaires. A total of 217 farmers were interviewed, 157 farmers from Thaba Nchu and 60 farmers from Botshabelo. These two districts are dominated by small-scale livestock production and it represent a major source of livelihood for the farmers in the areas. The interviews captured sheep production activities for the 2016/2017 production season. A proportionate stratified random sampling approach was used in Thaba Nchu. A complete list of all villages in Thaba Nchu was requested and obtained from the Department of Agriculture. Villages with the most sheep farmers were identified in the different areas and categorised into sub-groups. Seven farmers were chosen from each village in the different subgroups, making a total of 21 farmers per sub-group. As a result, 168 farmers were interviewed in Thaba Nchu. Due to incomplete information from some respondents, only 157 responses were eligible (complete) for this study. A complete list of the villages with sheep farmers could not be obtained from the Department of Agriculture in Botshabelo. Therefore, a simple random sampling technique was used to select sheep farmers from two areas known for sheep farming (Bradford farm and Naledi Commage. Sixty sheep farmers were selected at random and interviewed, and all their responses were eligible for the study.

The questionnaires were designed to capture relevant input-output data of smallholder sheep farmers. Questions included farmers' sheep production (sheep value in South African Rand (ZAR), flock size (animals), size of grazing land (ha), amount of labour (hired and family labour in mandays), amount spent on animal health services (ZAR) and amount spent on feed (ZAR), operating and transportation costs, management practices or grazing systems (access to communal land or access to tenured land), and choice of breed. Other relevant information, such as socio-economic and institutional variables, were also captured. The socio-economic variables captured included age, gender, household size and education, while the institutional variables included extension services, veterinary services, access to credit, distance to the nearest market and land tenure systems. It was noticed that farmers within the study areas do not always keep proper records of farming incomes and expenses. However, some of the information, especially price information and the information on the number of animals sold were obtained from the extension officers who keep some records on the farmers' production activities. 
138

139

140

141

142

143

144

145

146

147

148

149

150

151

152

153

154

155

156

157

158

159

160

161

162

163

164

165

166

167

\subsection{Socio-economic and Institutional Characteristics of Respondents}

The survey results the average sheep output was R 2972 and R 3023 for Thaba Nchu and Bostabelo respectively. The respondents indicated that the average purchase price for sheep was R 1320 and R 1250 for Thaba Nchu and Botshabelo respectively. Conradie and Piesse (2015) found sheep farmers in Laingsburg, South Africa, to have a sheep output of R 664 on average per year. Furthermore, sheep farmers in Thaba Nchu spent R861.39 on average per month on veterinary drugs, while farmers in Botshabelo spent R670.83. Veterinary drugs enhance the health of the sheep, which will increase the productivity of the sheep. Spending more money on veterinary drugs could increase sheep output. A study by Otieno et al. (2012) found that smallholder cattle farmers in Kenya spent the equivalent of R5 633.93 per year. Nyam et al. (2019) found that an increase in veterinary cost would reduce the technical efficiency of sheep farmers in Thaba Nchu and Botshabelo.

Farmers in Botshabelo spent, on average, R 466 on operating expenses on their farms per month, while farmers in Thaba Nchu spent R417.79 per month on operating expenses. Distance to a market was measured in kilometres from the farmer's house to the nearest market centre. Sheep farmers in Botshabelo travelled shorter distances (on average $4.8 \mathrm{~km}$ ) to the nearest market centre than farmers in Thaba Nchu (5.69 km). Shomo et al. (2015) found that small-scale sheep farmers in Syria where approximately $46.33 \mathrm{~km}$, on average, from the nearest market. The grazing land (measured in hectares (ha)) per farmer in Botshabelo (425.33 ha) is on average larger than that in Thaba Nchu (353.26 ha). Even though the survey data indicates that the sheep farmers in Botshabelo are operating on a more grazing land than in Thaba Nchu, there is a high variability ( $\mathrm{SD}=553.819$ ) between the sizes of grazing land used by farmers in Thaba Nchu and Botshabelo ( $\mathrm{SD}=76.429$ ). This means that some farmers in Thaba Nchu graze on larger pieces of land (Max. $=2486$ ha) than others (Min. = 15 ha). Conradie and Piesse (2015) found that sheep farmers in Laingsburg grazed on 12.58 hectares of land, on average, with a standard deviation of 4.88 . Shomo et al. (2015) found sheep farmers in Syria grazed on 6.05 ha. Farmers along the N8 development therefore have relatively larger grazing land because they are grazing on communal land without title deeds.

Sheep farmers in Botshabelo were older, on average, than farmers in Thaba Nchu. The average age of the farmers was 57 years in Botshabelo, and 54 years in Thaba Nchu. The results also 
168

169

170

171

Table 1: Socio-economics and institutional characteristics of sheep production

\begin{tabular}{|c|c|c|c|}
\hline \multirow{3}{*}{ Variables } & \multicolumn{3}{|c|}{ 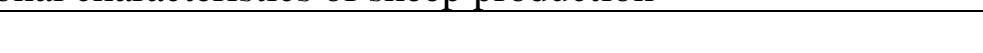 } \\
\hline & Thaba Nchu & Botshabelo & Pooled \\
\hline & $(\mathrm{N}=157)$ & $(\mathrm{N}=60)$ & $(\mathrm{N}=217)$ \\
\hline \multicolumn{4}{|c|}{ Profit efficiency function } \\
\hline $\begin{array}{c}\text { Value of sheep output (Rand per } \\
\text { year) }\end{array}$ & $2972(1656)$ & $3023(2669)$ & $2997.5(5535)$ \\
\hline Average sheep price (Rand) & $1320(4125)$ & $1250(3150)$ & $1866(5059)$ \\
\hline Veterinary cost (Rand per month) & $861.39(1$ 1 170.79) & $670.83(735.16)$ & $766.11(952.9)$ \\
\hline Operating cost (Rand per month) & $684(1216)$ & $466(234)$ & $575(725)$ \\
\hline Feed cost (Rand per mouth) & $685.37(774.85)$ & $543.22(625.32)$ & $614(700.09)$ \\
\hline \multicolumn{4}{|c|}{ Profit inefficiency function } \\
\hline Distance to market (kilometres) & $5.69(8.963)$ & $4.8(6.635)$ & $5.24(7.80)$ \\
\hline Communal land size (hectares Ha) & $353.26(2486)$ & $425.33(850)$ & $389.30(1668)$ \\
\hline Age & $54(25)$ & $57(30)$ & $55.5(27.5)$ \\
\hline Gender ( $\%$ female farmers) & $36.9 \%$ & $26.7 \%$ & $34.1 \%$ \\
\hline Family Labour (man-days) & $8(13)$ & $18(21)$ & $13(16.5)$ \\
\hline $\begin{array}{c}\text { Educational level (years of formal } \\
\text { education) }\end{array}$ & $7(3)$ & $6(3)$ & $7(3)$ \\
\hline $\begin{array}{c}\text { Sheep loss (number of sheep lost } \\
\text { due theft or disease per year) }\end{array}$ & $11(18)$ & $13(21)$ & $12(19)$ \\
\hline Farm experience (years) & $13(12)$ & $11(8)$ & $12(10)$ \\
\hline Herd Size (number of sheep) & $24(25)$ & $27(27)$ & $26(26)$ \\
\hline
\end{tabular}

172

Note: 1 USD = R 15.00 (ex.com 2020). Values in bracket represent standard deviation

demonstrates that sheep farmers in Thaba Nchu had more experience (average 13 years) in sheep production than those in the Botshabelo (average 10 years). Farmers in Botshabelo have, on average, three more sheep (27) than farmers in Thaba Nchu, who have 24 sheep on average.

3.2. Methodological Approach

\subsubsection{Empirical Model}

175 The stochastic profit frontier used in this study requires two stages. The proposed stages involves

176 the explanation of each observation's unit profit performance in terms of technical and allocative 177 efficiency in the first stage and the second stage explains differences in efficiency in terms of farm178 specific variation. The frontier production function is a very popular method for measuring the 179 technical efficiency of farms (Nganga et al. 2010). Measuring the profit efficiency of farmers is 
180 important because it examine factors that have a direct influence on sheep production and profit 181 efficiency.

182 The value of sheep output measured in this study is in Rand value and shows the levels of profit 183 efficiency of sheep production for the 2016/2017 production year. It shows that even though the 184 smallholder farmers produce at small scale, they equally make profits though not enough to sustain 185 their livelihoods in some instances (Nyam et al. 2019). Profit efficiency is defined in this study as 186 revenue gained from sheep production, taking farm-specific prices and associated costs into 187 188 189 190 account. Given that smallholder sheep farmers in the study area operate to maximize profit in other to uplift their livelihoods, it is important to consider all factor inputs required to produce the desired sheep output. This according to Batha and Baker (2015) is subject to perfectly competitive input and output markets and the level of technology. Considering the fixed and variable costs, the actual profit function be derived as follows:

192 The stochastic profit function of smallholder sheep farmers can be estimated in terms of gross 193 margin (GM) per farm. GM equals total revenue (TR) from sheep production minus total variable 194 cost (TVC) incurred in sheep production, that is (GM= TR - TVC). The profit function follows 195 Batha and Baker (2015) and is specified as:

$$
\begin{aligned}
& G M_{C \pi)}=\sum(T R-T V C)=\sum\left(P Q-W X_{i}\right) \\
& \frac{\pi}{p}(P, Z)=\frac{\sum\left(P Q-W X_{i}\right)}{P}=Q-\frac{W X_{i}}{P}=f\left(X_{i}, Z\right)-\sum P_{i} X_{i} \\
& G M_{(\pi)}=\sum(T R-T V C)=\sum\left(P Q-W X_{i}\right)
\end{aligned}
$$

197 Where TR is the total revenue from sheep production, TVC are the related variable cost incurred 198 in the sheep production process (operating cost, feed cost, veterinary cost, sheep purchase cost, 199 etc.), per farm i; Q is sheep output; X represents the (optimal) quantity of input used; W represent 200 the cost of inputs $\left(\mathrm{WX}_{\mathrm{i}}=\right.$ number of inputs*price of inputs), $\mathrm{Z}$ represents fixed inputs, while $\mathrm{f}\left(\mathrm{X}_{\mathrm{i}}\right.$, 201 Z) represents the production function.

202 The choice of functional form is very important when specifying the model, as it can influence the 203 results of the estimated efficiency (Ogundari et al. 2010). Functional forms, like linear models, 204 semi-log models, trans-log and the Cobb-Douglas have been used in other studies (e.g., Aung 
205 2011; Ogundari 2008). However, the Cobb-Douglas profit function was chosen for this study 206 because the functional form provides a better fit for the data.

207 The Cobb-Douglas profit function used in the study is expressed as:

208 $\pi_{i}=f\left(p_{i}, Z\right) \exp \left(v_{i}-u_{i}\right) \square_{i}=1,2,3, \ldots \ldots . . n$

209 Where $\pi_{i}$ is the gross margin, $P_{i}$ is the price of inputs while $\mathrm{Z}$ represent fixed inputs. $V_{i}-U_{i}$

210 denotes the total deviation, which is independent of each other. $V_{i}$ is a symmetric two sided 211 normally distributed random error that accounts for the random effects beyond the farmers' control 212 (e.g. temperature, diseases and parasites, natural hazards, omitted variables, measurement error 213 and other statistical noise) (Coelli et al. 2005). The systematic random-error component $\left(V_{i}\right)$ is 214 assumed to be independently and identically distributed with zero mean and variance (Battese and 215 Broca, 1997). $U_{i}$ denotes the asymmetric non-negative random-error component that measures 216 technical inefficiency. The non-negative variable $U_{i}$ is assumed to be independently and 217 identically distributed truncations (at zero from below) of the $N\left(m_{i}, \sigma_{U}^{2}\right)$ distribution, where $218 m_{i}=Z_{i k} \Phi_{k} \cdot \Phi_{k}$ is a vector of parameters to be estimated and $Z_{i k}$ is a vector of variables that may 219 influence inefficiency of the sheep farmers (Coelli et al. 2005; Greene 2003; Otieno et al.,2012).

220 According to Battesse and Coelli (1995), estimating the profit frontier function captures profit of 221 individual farms and farm specific inefficiencies. The Cobb-Douglas profit function is specified 222 as:

$223 \ln \pi=\ln \beta_{0}+\beta_{1} \ln C_{1 i}+\beta_{2} \ln C_{2 i}+\beta_{3} \ln C_{3 i}+\beta_{4} \ln C_{4 i}+\beta_{5} \ln C_{5 i}+\left(v_{i}-u_{i}\right)$

224 Where $\pi$ represents the profit, $\mathrm{C}_{1}$ represents operating costs, $\mathrm{C}_{2}$ represents veterinary cost, $\mathrm{C}_{3}$ 225 represents feed cost, $C_{4}$ represents fixed cost, $C_{5}$ represents sheep purchase cost, and $\beta$ 's are the 226 unknown parameters to be estimated. As earlier indicated, the non-negative random variable $\left(u_{i}\right)$ 227 is independently distributed with a truncation at zero of the normal distribution, $N\left(m_{i}, \sigma_{U}^{2}\right)$ with 228 mean $\mu$, where $m_{i}=Z_{i k} \Phi_{k} . \Phi_{k}$ as defined below. 
229 The technical inefficiency effects $\left(u_{i}\right)$ defined in equation (3) is specified as:

230

$u_{i}=\phi_{0}+\sum_{i=1}^{10} \phi_{k} Z_{i k}+v_{i}$

231 where $v_{i}$ represent the inefficiency error term and $Z_{i k}$ are the inefficiency variables (gender of 232 household head (dummy), education of household head, age of household head, household size, 233 extension services received, annual household income, capital availability, and herd size measured

234 in sheep numbers owned) observed for farm i. Furthermore, $\phi_{0}$ is a vector of unknown coefficients 235 to be estimated simultaneously with production function specified in equation 3.

236 Sigma-squared $\left(\sigma^{2}\right)$ and gamma $(\gamma)$ are variance parameters that will also be estimated. The 237 gamma value is used to determine the presence of inefficiency in the production data. For example, 238 a gamma value of 0.7 shows that $70 \%$ of the variation in sheep production would be because of 239 technical inefficiency (Coelli et al. 2005). The gamma value can be used to gauge for the presence 240 of technical inefficiencies in the data.

$241 \gamma=\sigma_{u}^{2} /\left(\sigma_{v}^{2}+\sigma_{u}^{2}\right)$

242 The sigma squared $\left(\sigma^{2}\right)$ value is used to determine if the distributional assumption of the 243 inefficiency effect is correctly specified. It follows that (Aigner et al. 1977):

$244 \quad \sigma_{u}^{2}=\left(\sigma_{v}^{2}+\sigma_{u}^{2}\right)$

245 The variance parameters of the model were also specified as:

$246 \gamma=\frac{\sigma_{u}^{2}}{\sigma^{2}}$ Such that $0<\gamma<1$

247 The Cobb-Douglas profit function specified in Equation (3) shows the profit efficiency ( $\left.\mathrm{PE}_{\mathrm{i}}\right)$ of 248 the $\mathrm{i}^{\text {th }}$ sheep farm in the production frontier which can be defined as the ratio of observed output 249 to the expected maximum level from the use of inputs available, given that there is no technical 250 inefficiency in production (Battese and Coelli 1988). From the above definition, $P E_{i}$ can be 251 expressed mathematically as (Boshrabadi et al. 2008): 
$252 \quad P E_{i}=\frac{Q_{i}}{Q_{i}^{*}}=f \frac{\left(x_{i k} ; \beta_{k}\right) e^{\left(U_{i}-V_{i}\right)}}{f\left(x_{i k} ; \beta_{k}\right) e^{(V)}} e^{-U}$

253 Battese and Coelli (1988) derive the best predicator of PE from Equation (4) and specify it as 254 follows:

$255 P E_{i}=E\left[\exp \left(-U_{i}\right)\right] 0 \leq P E_{i} \leq 1$

256 The profit frontier and inefficiency functions specified in equations (3) and (4) were estimated 257 jointly using FRONTIER 4.1 (Coelli 1996). It combines the two-stage procedure: the maximum 258 likelihood method estimates the parameters of the profit function, and those of the inefficiency 259 model (Bahta and Baker, 2015). The simple OLS and ML were fitted to determine whether the 260 profit efficiency in sheep production in N8 development corridor is affected by farm-specific 261 characteristics. The simple OLS function do not account for efficiency effects (i.e. $U_{i}=0$ ), while 262 the stochastic frontier production function accounts for the total variation of output due to technical 263 inefficiency. In the ML model, $\gamma \neq 0$ (Ngwenya et al. 1997). All hypotheses tests were carried out 264 using the generalised likelihood-ratio test. The test statistics $(\lambda)$ is defined as (Coelli 1995):

$$
\lambda=-2\left[L\left(H_{0}\right)-L\left(H_{a}\right)\right]
$$

Where $L\left(H_{0}\right)$ and $L\left(H_{a}\right)$ are the values of the log likelihood functions for unrestricted $\left(H_{0}\right)$ and the restricted ( $H_{a}$ ) models (Coelli 1995). The test statistics have an approximately asymptotic

268 chi-square or mixed chi-square $\left(X^{2}\right)$ distribution with degrees of freedom equal to the number of parameters specified to be zero in the null hypothesis. The Kodde and Palm chi-square distribution tables were used to obtain the critical values. The estimated test statistics were compared to the

271 Kodde and Palm (1986) critical values at a 5\% significance level. The null hypotheses are rejected 272 if the $X^{2}$ statistic estimated exceeds the $X^{2}$ critical value. 
278

279

280

281

282

283

284

285

286

287

288

289

290

291

292

293

294

295

296

297

298

299

300

301

302

303

304

305

\section{Discussion of Results}

\subsection{Profit Efficiency Function Estimates}

The profitability parameter estimates for sheep production for the stochastic profit function is presented in Table 2. The results of the stochastic profit functions were pooled together to have single profit function for both Thaba Nchu and Botshabelo.

Profit inefficiency is measured by the value of gamma $(\gamma)$ and was estimated using the generalized Log Likelihood Ratio test. Table 2 shows that the estimated value of gamma is greater than zero, suggesting that variations in profit efficiency is as a result of both production inefficiency and external factors uncontrolled by the farmer, random shocks and measurement errors. Generally, the variation in sheep production for the study areas is primarily as a result of profit inefficiency on the part of the sheep farmers, as explained by the gamma value for the pooled sample. The implication is that the average production function, which has no profit inefficiency effects, is not an adequate representation of the data (Battese et al. 1996). The gamma value for pooled profit function is 0.698 and is significant at $1 \%$. The implication is that PE is a significant contributor to the total deviation of output. This means therefore that inefficiency contributes to $68.9 \%$ of the variation in the dependent variable. The generalized Log Likelihood Ratio test was performed at $5 \%$ level of significance and 9 degrees of freedom. The value of the test was significantly higher critical values on the Kodde and Palm Chi-square table (Kodde and Palm 1986). The $\sigma^{2}$ value is significant meaning that the technical efficiency equation can explain the differences between each farm's profit and the profit on the frontier function (Bahta and Baker 2015). Table 2 presents the stochastic profit frontier; the parameter estimates and the level of significance. The profit frontier is the first stage of the estimation.

The effects of all production costs is positive except for operating and purchase cost, which are negative. However, operating cost is not statistically significant. Feed cost has a significantly positive effect on profits in the sample. This result is against expectation as it is assumed that profit will increase with falling input prices. The implication of this result is that, as farmers' increase their herd size, the cost of feed will increase to complement the herd size, which will increase sheep production. This result is consistent with Nganga et al. (2010) who found a positive 
306 relationship with feed cost and milk profit in Kenya. However, Bahta and Baker (2015) and Tijani

307 et al. (2006) found a negative relationship between feed cost and beef profit in Botswana.

308 Table 2. Stochastic Profit Frontier Estimates

\begin{tabular}{|l|l|l|l|}
\hline Variables & Parameters & coefficients & Prob \\
\hline Constant & $\beta_{0}$ & $3.140^{* * *}$ & 0.000 \\
\hline Ln (Operating cost) & $\beta_{1}$ & -0.078 & 0.146 \\
\hline Ln (Veterinary cost) & $\beta_{2}$ & 0.039 & 0.513 \\
\hline Ln (Feed cost) & $\beta_{3}$ & $0.156^{* * *}$ & 0.000 \\
\hline Ln (Purchase cost) & $\beta_{4}$ & $-0.547^{* * *}$ & 0.000 \\
\hline Ln (Fixed cost) & $\beta_{5}$ & $0.419^{* * *}$ & 0.000 \\
\hline \multicolumn{2}{|c|}{ Diagnostic statistics } & & \\
\hline Sigma square & $\sigma^{2} \sigma_{v}^{2}+\sigma_{u}^{2}$ & $0.331^{* * *}$ & 0.000 \\
\hline Gamma & $\gamma=\frac{\sigma_{u}^{2}}{\sigma^{2}}$ & $0.698^{* * *}$ & \\
\hline Observation & LF & -193.82148 & \\
\hline
\end{tabular}

309 Note: $* * *, * * *$ Significant at $10,5,1 \%$ level respectively.

310 The negative sign associated with purchasing cost (include cost of buy sheep) was highly expected.

311 This implies that as the cost of purchasing sheep goes up, sheep production decreases. This cost

312 will the increase cost of producing one unit of sheep and as a result reduce the profits farmers

313 would receive per unit of sheep. However, fixed cost has a positive impact on sheep production.

314 This implies that as fixed cost increase, sheep production will equally increase. This result was

315 highly unexpected given that that this set of farmers are operating on a small scale and do not enjoy

316 the benefits of economies of scale. This results is consistent with Bahta and Baker (2015) who

317 found fixed cost to have a positive influence of small scale beef production in Botswana

318 4.2. Determinants of Profit Inefficiency among Sheep Farmers 
319 The second stage was to identify factors that determine the producers' level of profit efficiency 320 (PE). The estimates of the determinants of profit inefficiency of sheep in the study area are 321 presented in Table 3. Since the parameters of the inefficiency levels enter the production model as 322 dependent variables, a variable with a negative sign in the inefficiency parameters means the 323 corresponding variable reduces inefficiency or increases efficiency (Otieno et al. 2012). On the 324 other hand, a positive variable in the inefficiency model is seen to negatively affect or influence 325 efficiency (Coelli et al. 2005).

326 The results in Table 3 show that Extension services (5\%), and educational level (5\%) would 327 significantly increase PE in sheep production in the study area. The results show that educational 328 level had positive relation to PE in the study area and is significant at 5\%. This implies that the 329 more educated a farmer is, the more efficient the farmer becomes. Most farmers in the study area 330 have undergone formal education, though not to high levels. This means that farmers have some 331 level of formal training, which helps them with sheep production. However, Bahta and Hikuepi 332 (2015) and Otieno et al. (2012) found that educational level decreases TE of cattle production. 333 Bahta and Hikuepi (2015) explained, further, that the more educated a farmer becomes, the more 334 the farmer engages in activities other than cattle production, thereby reducing the efficiency of the 335 farmer. Mensah and Brummer (2016) also found educational level to reduce TE in mango 336 production in northern Ghana.

337 Extension services has a negative coefficient in the results, indicating that an increase in extension 338 services will increase PE in the study area. This result is highly expected, as extension services is expected to equip farmers with better production techniques and market information, among other benefits, which will lead to an increase in PE. Furthermore, if extension officers have been trained properly and have experience, they can provide farmers with accurate information, which will assist the farmers in production and increase the PE of farmers. This result is consistent with Nyam et al. (2019) who found that access to extension services reduces technical inefficiency in sheep production among smallholder farmers. 
349 Table 3. Determinants of Profit Inefficiency among Sheep Farmers

\begin{tabular}{|l|c|c|c|}
\hline Variables & Parameters & coefficients & Prob. \\
\hline Constant & $\delta_{0}$ & $-8.745^{* * *}$ & 0.000 \\
\hline Gender (female) & $\delta_{1}$ & $3.811^{* *}$ & 0.050 \\
\hline Age & $\delta_{2}$ & 0.009 & 0.824 \\
\hline Household size (below 18) & $\delta_{3}$ & $1.628^{* *}$ & 0.029 \\
\hline Household size (above 18) & $\delta_{4}$ & -0.045 & 0.886 \\
\hline Extension services (Yes=1; No=0) & $\delta_{5}$ & $-7.772 * *$ & 0.024 \\
\hline Annual household income & $\delta_{6}$ & 0.248 & 0.611 \\
\hline Herd size & $\delta_{7}$ & 0.825 & 0.563 \\
\hline Years of education & $\delta_{8}$ & $-0.691 * *$ & 0.043 \\
\hline Capital availability & $\delta_{9}$ & 0.805 & 0.264 \\
\hline Sheep loss (theft and diseases) & $\delta_{10}$ & $0.163 * * *$ & 0.000 \\
\hline
\end{tabular}

Note: $* * *, * * *$ Significant at 10, 5, $1 \%$ level respectively. A parameter with a negative sign in

the inefficiency means signifies that the associated variable has a positive effect on the economic efficiency and vice versa.

353 Sheep loss has an expected influencing on profit efficiency. Sheep loss is one of the constraints affecting smallholder farmers' performance and efficiency (Nyam et al. 2019). This result was expected because sheep loss due to theft (which is very high in the study area) and diseases will significantly reduce sheep production and subsequently profit all things being equal. Diseases and parasites contribute significantly to livestock loss and profit among smallholder farmers (Bahta and Baker 2015). Household size (members younger than 18) has a positive and significant coefficient at $5 \%$ level of significance. The significance of this result means that household with members younger than 18 years old reduces PE. This result could be explained by the fact that farmers in the study area depend on family labour for sheep production and individuals younger than 18 years are considered too young to engage in farming activities. This result is consistent with the findings of Nganga et al. (2010). However, Ojo et al. (2020) found household size to 364 positively influence smallholder rice farmers in Nigeria. 
365 The coefficient for gender (female) is positive and significant at 5\% level of significance. This 366 implies that female sheep farmers are less efficient compared to male farmers. The fact female 367 head of households are often engaged in household and farming activities could explain this result. 368 They are less likely to fully engage in sheep production thereby reducing their profit efficiency. 369 This result is consistent with Ojo et al. (2020) who found gender to have positive influence on 370 profit inefficiency among smallholder rice farmers in Nigeria. However, Bahta and Baker found a 371 negative relationship between gender and profit inefficiency.

372 Figure 2 shows the inefficiencies estimates of sheep farmers in the study area. Furthermore, Table 3734 also shows the descriptive statistics for the profit efficiency scores.

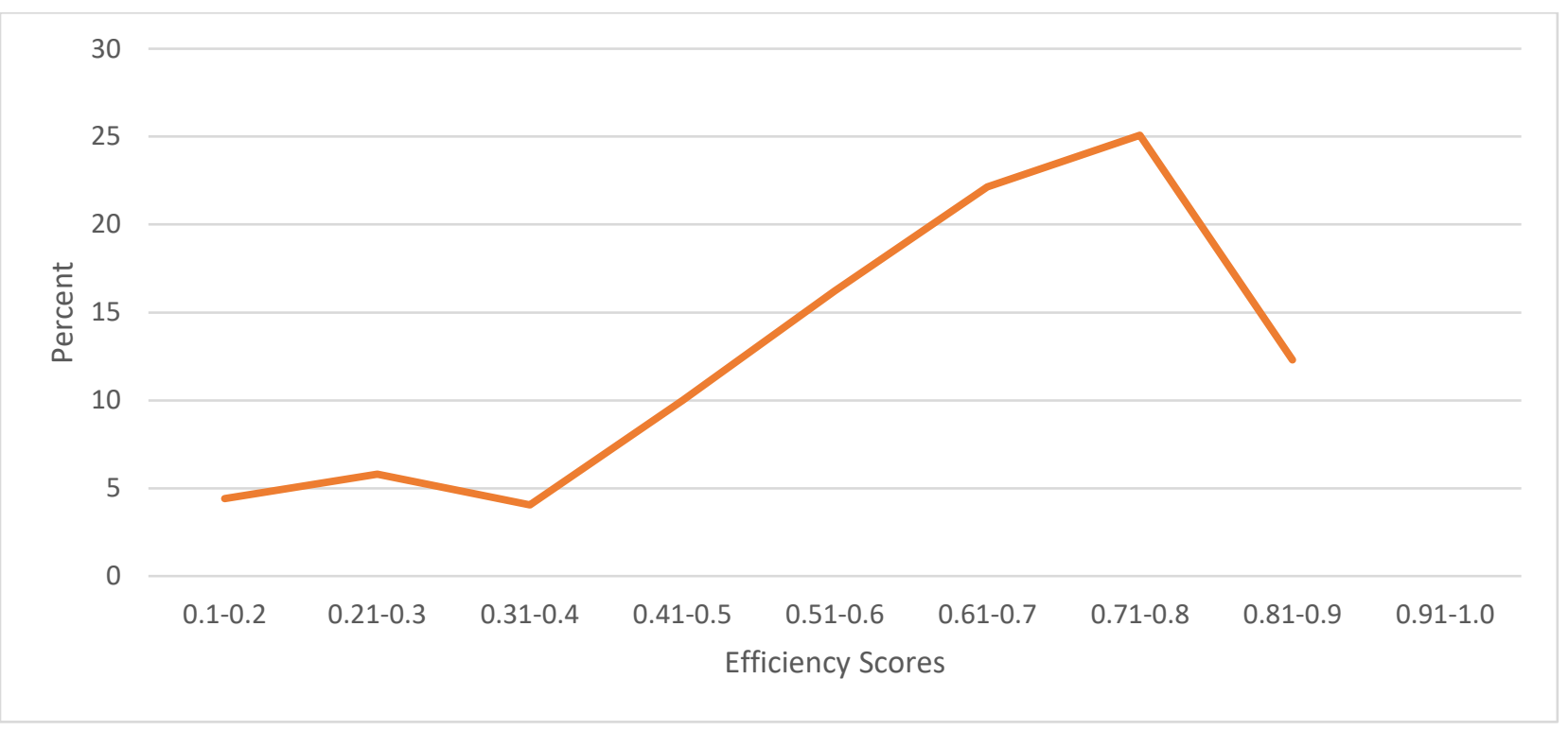

375 Figure 2: Distribution of farm specific profit efficiencyscores

376 The average profit efficiency score is 0.651 for the sample with most of the scores lying between 3770.71 to 0.8 . This indicates that there is a considerable scope to improve sheep profitability using 378 available input at market prices and production technology among sheep farmers in the N8 379 development corridor. The average efficiency score of $65.1 \%$ means that on the average an 380 estimated $34.9 \%$ of the farm profit is lost to economic inefficiency. This value of the $34.9 \%$ shows 381 that smallholder sheep farmers can improve both their economic and allocative efficiencies. 
Table 4: Summary of Profit Efficiency Scores for Sheep Production

\begin{tabular}{|l|c|}
\hline Statistics & Efficiency score \\
\hline Average & 0.651 \\
\hline Minimum & 0.155 \\
\hline Maximum & 0.804 \\
\hline Standard deviation & 0.159 \\
\hline
\end{tabular}

385

386

387

388

389

390

391

392

393

394

395

396

397

398

399

400

401

402

403

404

405

406

407

408

409

410

\section{Conclusion and Policy Recommendation}

This study used a stochastic profit frontier model examine the profitability of sheep farmers and to identify the determinants of profit efficiency in smallholder sheep production in the N8 development corridor. It can be concluded from the results of the study that farmers in the study area are producing well below the production frontier indicated by the average PE scores obtained. This means that farmers have the potential to increase their profitability and efficiency and produce at full capacity. The gamma values estimated show that a considerable variation in sheep production efficiency in the study area is caused by technical inefficiencies and, to a lesser extent by statistical noise or random shocks.

The stochastic profit function was estimated in the first stage, followed by the inefficiency function and the PE scores. Farmers in study area obtained an average PE score of $65.1 \%$, meaning they have a $34.9 \%$ potential to increase production at full capacity and enhance profitability. The profit frontier results show the variables that influence sheep production in the study area. The profit frontier revealed that feed cost, sheep purchase cost and fixed cost were the most important inputs for sheep production. These factor inputs were positive and significant. This means that an increase in feed cost, purchase cost and fixed production cost will cause sheep output to increase. It should be noted this results goes against expectation because increasing input prices will increase cost of production and if this increase in production cost is not followed by increase in output prices, profitability of the farmers will reduce. It is hypothesised that farmers want to maximise profit by minimising cost of production.

Furthermore, the inefficiency shows that extension services and educational levels of household head will increase profit efficiency in the study area. Extension services is negative and significant at 5\% level. This means an increase in extension services will increase profit efficiency of the farmers. Educational level of household heads is negative and significant at 5\% level. This means an increase in the educational level of the household head will increase profit efficiency in the 
411 study area. However, gender (female) and household size (under 18 years) were positive and

412 significant. This means an increase in either gender or household size (under 18 years) will reduce 413 profit efficiency of the farmers.

414 The analysis of profit efficiency in this study indicate that improvement in extension services, 415 education and training of farmers can contribute significantly to smallholder sheer producers'

416 profit efficiency. Sheep loss due to theft and diseases is still a major constraint inhibiting the ability 417 of sheep farmers to increase production and profit and therefore should an area of government 418 concern. Assisting sheep farmers to build shelters to keep their sheep and subsiding the cost of 419 veterinary drugs will go a long way in reducing sheep losses. The results presented in this study 420 has shown that smallholder sheep farmers lack the skills to sustainably manage their farm 421 operation in order to be profitable. The government, through the Department of Agriculture, should 422 organise training workshops and seminars on appropriate management skills to support the 423 decision-making of sheep farmers on the efficient use of farm resources and the coordination of 424 their farm operations. Farmers should be provided with livestock extension training on farm 425 management and keeping proper records of their activities. Extension officers should present 426 demonstration workshops on farms to encourage more experienced farmers to share their farm 427 knowledge with less experienced farmers. The government should subsidise the cost of veterinary 428 drugs and services so that farmers can have easier access to these services. This will help them 429 deal with diseases and parasites that affect their sheep. In the long run, farmers should be sensitised 430 on diseases and parasites that affect livestock and techniques of identifying and dealing with these 431 diseases.

432 Availability of data and materials

433 The data that support the findings of this study can be obtained from the authors upon request.

\section{Ethics approval and consent to participate}

435 The study received an ethical clearance and each participant signed a consent form

436 Funding: This research received from Intra-ACP STREAMS Mobility Scheme. This project 437 provided funds for the Masters research. 
438 Acknowledgments: The article is part of the Master's dissertation by Nyam (2017), entitled "A 439 Metafrontier Analysis of Sheep Production in the N8 Development Corridor". We are very grateful 440 to the enumerators and the farmers who sat patiently for hours providing responses to the 441 questionnaire.

442 Conflicts of Interest: The authors declare no conflicts of interest.

\section{Authors' contributions}

444 YSN structured the general research with the goals and aims. He equally designed the methodology 445 and models used in the research. TOO used statistical, mathematical, and computational techniques 446 to analyse or study data; JAB Drafted the introduction and study area of the study; AAO discussed 447 the results of the study and AAA edited the structure of the paper. All authors read and approved 448 the final manuscript.

\section{Reference}

(Pty)

Ltd.

(2019)

Free State

municipality

map.

https://www.google.com/maps/place/Lejweleputswa/@ 29.2060166,26.2508916,10z/data=!4m5!3m4!1s0x1e90f18049c54b5b:0xd8d7a5110dc3e56 $2 ! 8 \mathrm{~m} 2 ! 3 \mathrm{~d}-28.3991482 ! 4 \mathrm{~d} 26.2304616$ (accessed 9 February 2020).

Aung NM (2011) Agricultural efficiency of rice farmers in Myanmar: A case study in selected areas. Institute of Developing Economies (IDE) Discussion Paper No. 306.

Bahta S, Baker D (2015). Determinants of Profit Efficiency among Smallholder Beef Producers in Botswana. International Food and Agribusiness Management Review 18(3):107-120.

Bahta S, Bauer S (2012) Policy options for improving market participation and sales of smallholder crop producers: A case study of the Free State Province of South Africa. African Journal of Agricultural Research 7(24), 3525-3533. DOI: 10.5897/AJAR11.631.

Bahta S, Hikuepi K (2015) Measuring technical efficiency and technological gaps of beef farmers in three regions of Botswana: An application of meta-frontier approach. International Farm Management 20th Congress Quebec, Canada, 1(1):44-60. 
465

466

467

468

469

470

471

472

473

474

475

476

477

478

479

480

481

482

483

484

485

486

487

488

489

490
Battese G, Broca S (1997) Functional forms of stochastic frontier production functions and models for technical inefficiency effects: a comparative study for wheat farmers in Pakistan. Journal of Productivity Analysis 8(3):395-414.

Battese GE, Coelli TJ (1988) Prediction of firm-level technical efficiencies with a generalised frontier production function and panel data. Journal of Econometrics 38(1):387-399.

Battese GE, Coelli TJ (1995) A model for technical inefficiency effects in a stochastic frontier production function for panel data. Journal of Empirical Economics 20(2):325- 332.

Battese GE, Malik SJ Gill MA (1996) An investigation of technical inefficiencies of production of wheat farmers in four districts of Pakistan. Journal of Agricultural Economics 47(1):3949.

Boshrabadi HM, Villano RA Fleming E (2008) Technical efficiency and environmentaltechnological gaps in wheat production in Kerman province of Iran. Agricultural Economics 38:67-76.

Brundyn L, Brand TS, Ferreira AV, Aucamp BB, Durand A (2005) The effect of frequency of supplementation on the production of South African mutton Merino ewes grazing wheat stubble. South African Animal Science 6:13-18.

Coelli T, Rao DSP, Battese GE (2005) An Introduction to efficiency and productivity analysis, second edition. Boston: Kluwer Academic Publishers

Coelli TJ (1996) A guide to FRONTIER Version 4.1c: A computer program for stochastic frontier production and cost function estimation. Working Paper No. 7/97, Centre for Efficiency and Productivity Analysis (CEPA), School of Economics, University of New England, Armidale.

Conradie B, Piesse J (2015) Productivity benchmarking of free-range sheep operations: Technical efficiency, correlates of productivity and dominant technology variants for Laingsburg, South Africa. CSSR Working Paper No. 344. Pretoria: CSIR.

Davis J, Tavasci D, Marais L (2006) Fostering rural and local economic development in the Free State of South Africa. Natural Resources Institute, University of Greenwich, UK. 
491 Department of Agriculture, Forestry and Fisheries (DAFF) (2012) A profile of the South African 492 beef market value chain 2012.

493 Department of Agriculture, Forestry and Fisheries (DAFF) (2016) A profile of the South African $494 \quad$ beef market value chain 2016.

495 Dlamini BP (2014) Factors Affecting the Competitiveness of the Agribusiness Sector in 496 Swaziland. Journal of Agricultural Studies 2(1): 61-72. DOI: 10.5296/jas.v2i1.4775.

497 FAO (Food and Agricultural Organization) (2012) Livestock and food security in 2012. World $498 \quad$ Livestock and Food Security 95(5):1-191.

499 Greene WH (2003) Econometrics analysis, 4th ed. New Jersey: Pearson Education.

500 Kodde D, Palm FC (1986) Wald criteria for jointly testing equality and inequality restrictions: 501 Notes and comments. Econometrica 54(5):1243-1248.

502 Kyaw NN, Ahn S, Lee SH (2018) Analysis of the Factors Influencing Market Participation among 503 Smallholder Rice Farmers in Magway Region, Central Dry Zone of Myanmar. Sustainability 10, 4441. doi:10.3390/su10124441.

Mafukata MA (2015) Factors having the most significance on the choice and selection of marketing channels amongst communal cattle farmers in Vhembe District, Limpopo Province. Journal of Human Ecology 49, 77-87.

Maphalla LT, Salman MV (2012) Provincial report on education and training for agriculture and rural development: Free State province 2012. Free State: Department of Agriculture, Forestry and Fisheries.

511 Mawa LI, Kavoi MM, Baltenweck I, Poole J (2014) Profit efficiency of dairy farmers in Kenya: An application to smallholder farmers in Rift Valley and Central Province. Journal of

514 Mensah A, Brümmer B (2016) Drivers of technical efficiency and technology gaps in Ghana's 515 mango production sector: A stochastic metafrontier approach. African Journal of Agricultural and Resource Economics 11(2):101-117. 
517 Molotsi A, Dube B, Oosting S, Marandure T, Mapiye C, Cloete S, Dzama K (2017) Genetic Traits 518 of Relevance to Sustainability of Smallholder Sheep Farming Systems in South Africa. 519 Sustainability 9(8), 1225. Doi.org/10.3390/su9081225.

520 Mpandeli S, Maponya P (2014) Constraints and Challenges Facing the Small Scale Farmers in Limpopo Province, South Africa. Journal of Agricultural Science 6(4):135-143. Doi:10.5539/jas.v6n4p135

523

Ndoro JT, Mudhara M, Chimonyo M (2014) Cattle Commercialization in Rural South Africa: Livelihood Drivers and Implications for Livestock Marketing Extension. Journal of Human Ecology 45:207-221.

Ndoro JT, Mudhara M, Chimonyo M (2015) Farmers' choice of cattle marketing channels under transaction cost in rural South Africa: A multinomial logit model. African Journal of Range Forage Science 32:243-252.

Nganga SK, Kungu J, de Ridder N, Herrero M (2010) Profit efficiency among Kenyan smallholder milk producers: a case study of Meru-South district, Kenya. African Journal of Agricultural Research 5(3):332-337.

Ngarava S, Phetshe M, Mushunje A (2019) Market Awareness and Participation for Cattle Farmers in the Kaonafatso ya Dikgomo (KyD) Scheme in KwaZulu-Natal Province, South Africa. Agriculture 9:215. Doi:10.3390/agriculture9100215.

Ngwenya SA, Battese GE, Fleming EM (1997) The relationship between farm size and the technical inefficiency of production of wheat farmers in the Eastern Free State. Agrekon $36(3): 283-301$.

Nyam YS, Matthews N, Bahta YT (2019) Improving the livelihood of smallholder farmers through region specific strategies: a case study of South African sheep production. Agrekon 59(1):115. Doi:10.1080/03031853.2019.1639205.

Ogundari K (2008) Resource-productivity, allocative efficiency and determinants of technical efficiency of rainfed rice farmers: A guide for food security policy in Nigeria. Agricultural Economics Czech 54(5):224-233. 
544 Ogundari K, Amos TT, Ojo SO (2010) Estimating confidence intervals for technical efficiency of

545 rainfed rice farming system in Nigeria. China Agricultural Economic Review 2(1):107-118.

546 Ojo, TO, Ogundeji, AA, Babu, SC, Alimi T (2020) Estimating financing gaps in rice production 547 in Southwestern Nigeria. Journal of Economic Structures 9:12. Doi.org/10.1186/s40008$548 \quad$ 020-0190-y.

549 Otieno DJ, Hubbard L, Ruto E (2012) Determinants of technical efficiency in beef cattle 550 production in Kenya. International Association of Agricultural Economists (IAAE) Triennial Conference, Brazil 18-24 August 2012, 1-25.

552 Poole N (2017) Smallholder Agriculture and Market Participation; Practical Action Publishing: Rugby, UK, 2017.

554 Rege JEO, Marshall K, Notenbaert A, Ojango JMK, Okeyo AM (2011) Pro-Poor Animal 555 Improvement and Breeding_-What Can Science Do? Livestock Science 136:15-28.

556 Rios AR, Shively GE, Masters WA (2009) Farm production and household market participation: 557 Evidence from LSMS data. In Proceedings of the International Association of Agricultural Economist Conference, Beijing, China, 16-22 August 2009.

Shomo F, Ahmed M, Shideed KA, Hassan AW, Erkan O (2015) Sources of technical efficiency of sheep production systems in dry areas in Syria. Small Ruminant Research 91(1):160-169.

561 Tamirat M (2013) Econometric estimation of herd stocking decisions in South Ethiopia. Journal of Development and Agricultural Economics 5(8): 321-327.

563 Tijani AA, Alimi T, Adesiyan AT (2006) "Profit Efficiency among Nigerian Poultry Egg Farmers: A case study of Aiyetedo Farm Settlement, Nigeria” Research Journal of Agricultural Biological Sciences 2(6): 256-261. 
Figures

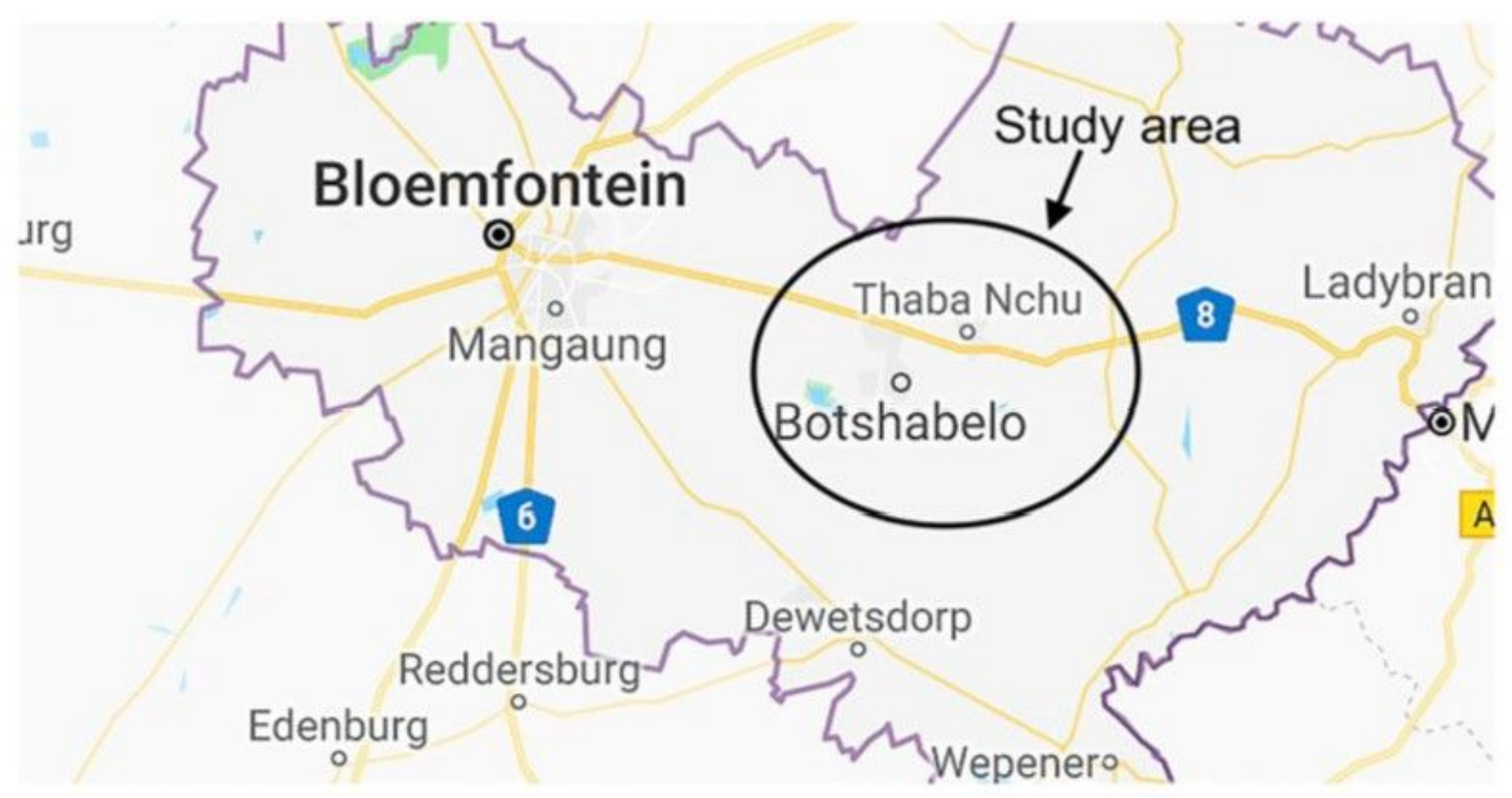

Figure 1

Map of the research area within the Mangaung metropolitan. Source: AfriGIS (Pty) Ltd. (2019).

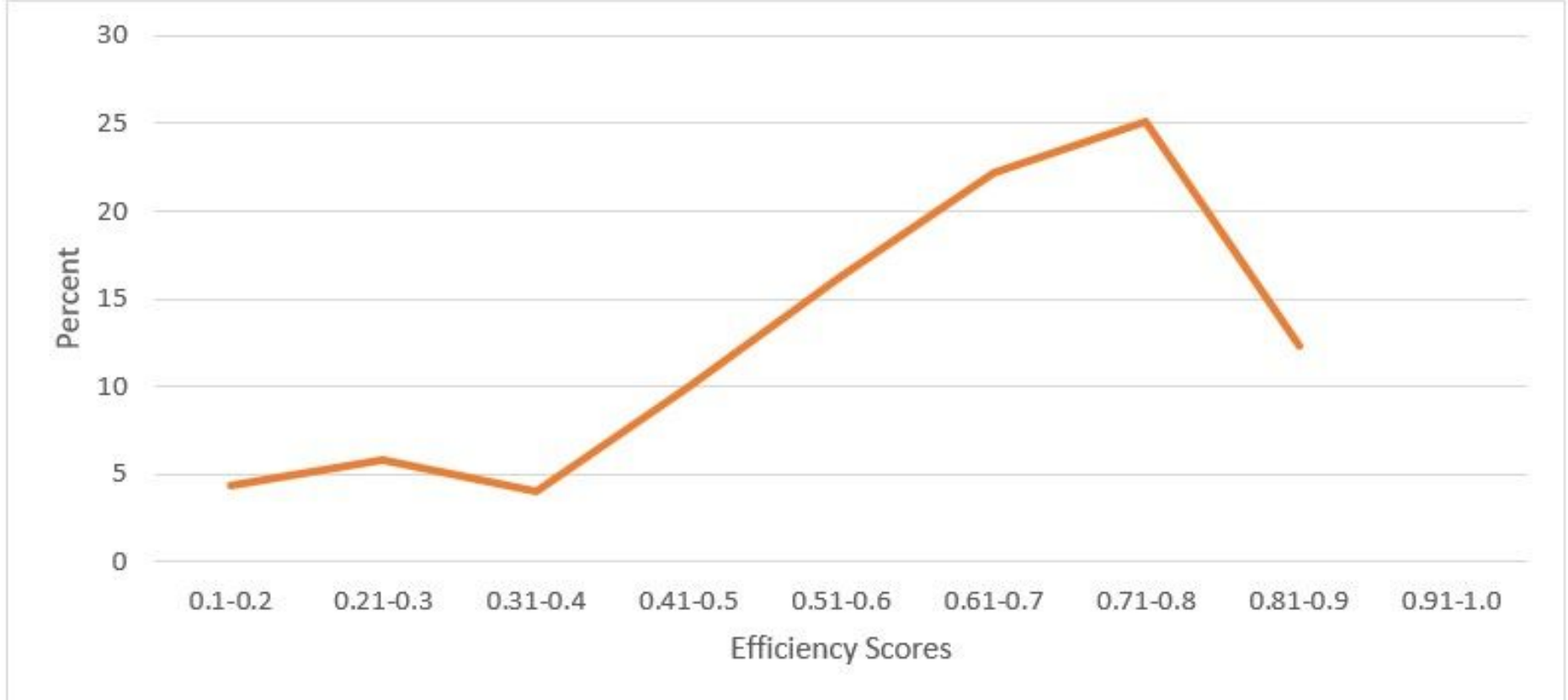

Figure 2 
Distribution of farm specific profit efficiencyscores

\section{Supplementary Files}

This is a list of supplementary files associated with this preprint. Click to download.

- AuthorDeclaration.docx

- AuthorDeclaration.docx 